\title{
TРАВМАТИЧЕСКИЙ ХИЛОПЕРИТОНЕУМ
}

\author{
B. Н. Войцехович, С. В. Доброквашин, А. А. Мустафин, Н. А. Герасимов,
} Ю. В. Бондарев, Н. Н. Лустина

Кафедра травматологии, ортопедии и военно-полевой хирургии (зав.- дои. Р. А. Зулкарнеев), кафедра дегской хирургии (зав.- проф. М. Р. Рокицкий) Казанского ордена Трудового Красного Знамени медицинского института имени С. В. Курашова, городская клиническая больница № 15 (главврач - Р. И. Туишев) 2. Казани

Хилоперитонеум - малоизученный и редкий вид патологии [7]. Лимфоистечение в брюшную полость может быть следствием травматического повреждения магистральных лимфатических сосудов брыжейки, а может и не иметь непосредственной связи с травмой. Клиническая картина хилоперитонеума многообразна и зависит от этиологического фактора и темпа лимфоистечения [2, 5].

Нетравматический хилоперитонеум возникает на фоне других заболеваний или пороков развития грудного протока и отличается подострым или хроническим течением. Ведущими симптомами являются увеличение живота, сопровождающееся недомоганием, слабостью, похуданием [3]. При травматическом хилоперитонеуме выражены болевой синдром и симптомокомплекс, сходный с клиникой «острого живота», но в то же время характерно отсутствие либо незначительная выраженность напряжения мышц передней брюшной стенки, обезвоженности и интоксикации при положительном симптоме Щеткина - Блюмберга. Наличие свободной жидкости в брюшной полости при физикальном обследовании можно определить только при скоплении значительного количества лимфы. В настоящее время на основании этиологии и патогенеза лимфоистечения [2, 5] выявлены клинические симптомы лимфоистечения, устанавливаемые при анализе крови,лимфопения, гипопротеинемия, сгущение крови.

В диагностике хилоперитонеума большое значение имеет пункция брюшной полости, или лапароцентез, с исследованием полученной жидкости. В большинстве случаев жидкость (отн. пл.- 1,012-1,028) бывает цвета молока с желтоватым - или красноватым оттенком и содержит большое количество белка (до 40 г/л), нейтральные жиры или кристаллы холестерина, эритроциты, лимфоциты. Рекомендации по тактике лечения больных при этой патологии существуют самые различные - от сугубо консервативных методов до экстренного хирургического вмешательства $[1,3,6,8]$. Выбор того или иного способа лечения зависит от причины и темпа хилореи с учетом общего состояния больных.

В городской клинической больнице № 15 г. Казани за последние 20 лет были прооперированы 458 взрослых с закрытой травмой живота и за 10 лет139 детей с открытыми и закрытыми повреждениями органов брюшной полости. У 2 больных из 597 был выявлен хилоперитонеум. Приводим наблюдения.

Г., 23 лет, поступил в хирургическое отделение 13.03 .86 г. через 1,5 часа после травмы. На работе был придавлен к стене бетонной плитой с эпицентром воздействия на мезогастральную область.

При поступлении жалобы на боли в левой половине живота, слабость. Сознание ясное, общее состояние удовлетворительное, кожные покровы бледные. АД - 14,6/10,6 кПа, частота пульса - 68 уд. в 1 мин, температура тела - $36,6^{\circ}$. Живот участвует в дыхании, мягкий и болезненный в левой половине, где определяется слабо положительный симптом Щеткина - Блюмберга. Перкуторно притупление в отлогих местах отсутствует.

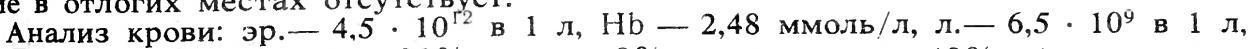
п.- $6 \%$, с.- $66 \%$, лимф.- $20 \%$, мон.-8\%, гематокрит-48\%. Анализ мочи отклонений не выявил. На обзорной рентгенограмме органов брюшной полости патологических "изменений не найдено.

С диагностической целью под местной анестезией произведены лапароцентез и исследование брюшной полости «шарящим» катетером. Добыта мутная жидкость, содержащая 21 г/л белка; в осадке - кровянистый сгусток; эритроциты покрывают поле зрения, единичные лейкоциты, кристаллы холестерина.

Через 4 часа после поступления сделан повторный анализ крови: эр.$5,2 \cdot 10^{12}$ в 1 л, Нb-2,32 ммоль/л, л.- 8,5 $10^{9}$ в 1 л, п. $-4 \%$, с.- $76 \%$, лимф. - $12 \%$, мон.- $8 \%$, гематокрит - $49 \%$. За время наблюдения в течение 6,5 ч из брюшной полости по катетеру выделилось 500 мл мутной жидкости белого цвета.

Диагноз: травматический хилоперитонеум.

Под общим обезболиванием с интубацией трахеи выполнена срединная лапаротомия с коррекцией доступа ранорасширителем М. З. Сигала и К. В. Ка- 
банова [4]. В брюшной полости выявлено около 500 мл жидкости молочного цвета; обнаружены разрыв брыжейки тонкого кишечника в области связки Трейца $(2,0 \times 0,5$ см $) ;$ хилезная имбибиция, распространявшаяся по корню брыжейки тонкого кишечника на брыжейку поперечной ободочной кишки с переходом на переднюю поверхность поджелудочной железы и к подкове двенадцатиперстной кишки. Поиск поврежденного лимфатического протока не увенчался успехом. После ушивания брюшины брыжейки видимая хилорея прекратилась. Брюшная полость санирована, осушена и дренирована двухпросветными трубками, введенными через отдельные проколы в левом подреберье и подвздошных областях.

После операции проводилась активная аспирация содержимого из брюшной полости. В первые 2 сут аспирировалось по 50 мл мутной, белесоватой жидкости. На 4-й день дренажи удалены. В течение 3 сут осуществляли парентеральную терапию с полным исключением энтерального питания. Рана зажила первичным натяжением. Выписан в удовлетворительном состоянии.

Анализ крови при выписке: эр.-4,6 - $10^{12}$ в 1 л, $\mathrm{Hb}-2,17$ ммоль/л, л.$5,8 \cdot 10^{9}$ в 1 л, п.-4\%, с.-58\%, лимф.-31\%, мон.- $7 \%$, гематокрит $-42 \%$. Осмотрен через месяц - жалоб нет. Здоров.

Б., 14 лет, поступил 30.03.86 г. через 7 дней после травмы - удара отверткой в живот. Со дня травмы и до поступления за медицинской помощью не обращался, вел обычный образ жизни.

При поступлении состояние средней тяжести. АД - 17,3/9,3 кПа, частота пульса - 90 уд. в 1 мин, температура тела $-37^{\circ}$.

По средней линии живота на 3 см выше пупка имеется колотая рана диаметром 0,3 см с ровными краями, не кровоточит. Из раны выступает прядь сальника. Беспокоят боли в животе и в области раны. Живот в дыхании участвует; при пальпации мягкий, умеренно болезненный в нижних отделах и в области раны; во всех отделах живота определяется слабо положительный симптом Щеткина Блюмберга.

Анализ крови: эр.- 3,5 $10^{12}$ в 1 л, $\mathrm{Hb}-2,17$ ммоль/л, л.-9,0 $\cdot 10^{9}$ в 1 л, п. $-17 \%$, с.- $69 \%$, лимф.-6\%, мон.-8\%, гематокрит - $45 \%$. На обзорной рентгенограмме органов брюшной полости патологических изменений не найдено. Диагноз - проникающая колотая рана живота.

Под интубационным наркозом произведена срединная лапаротомия. В брюшной полости обнаружено около 1000 мл хилезной жидкости, содержащей 26,4 г/л белка, кристаллы холестерина, эритроциты (покрывают все поле зрения), лейкоциты $(20-30$ в поле зрения). В области связки Трейца имеется ранение брыжейки тонкого кишечника $(0,5 \times 1,0$ см), откуда истекает жидкость белого цвета. Рана брыжейки ушита. Истечение лимфы прекратилось. Брюшная полость осушена, санирована, дренирована двухпросветными трубками в обеих подвздошных областях.

На 2-е сутки после операции анализ крови был следующим: эр.- 4,2 $\cdot 10^{12}$ в 1 л, $\mathrm{Hb}-2,02$ ммоль/л, л. $-9,0 \cdot 10^{9}$ в 1 л, п.- $17 \%$, с.- $69 \%$, лимф. $-6 \%$, мон.$8 \%$, гематокрит - 46\%. После операции в течение 3 сут проводили парентеральную терапию с исключением энтерального питания. В течение 2 сут из брюшной полости аспирировано по 30-50 мл мутной жидкости. Дренажи удалены на 4-й день. Рана зажила первичным натяжением. Анализ крови при выписке: эр.$3,6 \cdot 10^{12}$ в 1 л, Нb-2,02 ммоль/л, л.-4,0 $10^{9}$ в 1 л, эоз.-4\%, п.-4\%, с. $-56 \%$, лимф. - 30\%, мон.-6\%, гематокрит - $42 \%$. Выписан в удовлетворительном состоянии. Осмотрен через месяц - жалоб нет. Здоров.

В приведенных наблюдениях причиной хилоперитонеума был травматический разрыв лимфатических сосудов корня брыжейки: в первом случае, по-видимому, вследствие резкого повышения внутрибрюшного давления, во втором - в результате проникающего ранения с повреждением лимфатического сосуда (сосудов) небольшого калибра. Нарушение целостности брюшины корня брыжейки привело к истечению хилуса в брюшную полость. Реакция же брюшины на хилорею минимальна и на ранних сроках не сопровождается развитием перитонита. В связи с этим дооперационная диагностика хилоперитонеума представляет значительные трудности. При динамическом наблюдении за картиной крови имели место лимфопения и сгущение крови. Указанные выше симптомы объясняются лимфопотерей в объеме от 500 до 1000 мл.

Для уточнения диагноза необходимо рекомендовать лапароцентез с лабораторным исследованием полученной жидкости и лапароскопию для исключения повреждений органов брюшной полости, требующих экстренного хирургического вмешательства. При наличии у больного хилоперитонеума без сопутствующих повреждений органов брюшной полости показана консервативная терапия, так как обнаружить поврежденный лимфатический сосуд крайне трудно, а в областй десерозированных участков брюшины возникает спаечный процесс. 
Необходимо полностью исключить энтеральное питание, что ведет к остановке лимфореи (по мнению многих авторов $[1-3,5,8]$, оно увеличивает лимфообразование в 5 раз), проводить парентеральную терапию с обязательным включением в нее плазмозаменителей. Если больной прооперирован, то целесообразно дренирование брюшной полости трубчатыми дренажами для активной аспирации в послеоперационном периоде, а инфузионную терапию надо выполнять по указанному выше принципу.

Лимфопения, сгущение крови и гипопротеинемия, выявленные при исследовании крови в динамике, дают основание диагностировать лимфоистечение. При наличии у больных картины «острого живота» и лимфоистечения [2] следует заподозрить хилезный асцит, который в клинике протекает по типу апоплексии яичника. При исследовании содержания брюшной полости необходимо обращать внимание на цвет выпота, а при биохимическом его анализе - на наличие жира и белка.

\title{
ЛИТЕРАТУРА
}

1. Долецкий С. Я., Овчинников А. А., Мулина Ц. И.//Хирургия.- 1970.- № 6.С. 88-94.-2. Ибатулин И. А.//Там же.- 1977.- № 5.- С. $130-134 .-3$. Перельман М. И., Юсупов И. А., Седова T. Н.//Хирургия грудного протока.- М., Медицина, 1984.-4. Сигал М. 3., Кабанов К. В.//Бюлл. изобретений.-1959.- № 23.- 5. Татабадзе К. Г., Ибатулин И. А., Курбатов В.С. и др.//Хирургия.-1976.- № 12.- С. 37-38.-6. Ходиев Э. М., Хегай Е. Н., Шамсиев А. Ф. и др.//Вестн. хир.- 1984.- № 8.- С. 108-109.-7. Шубин В. Н.//Редкие хирургические болезни.- Изд-во Казанского ун-та, 1969.- 8. Vasko I., Tapper R.//Arch. Surgery.-1967.- Vol. 95.- P. 355.

Поступила 21.05 .86 .

удк $616.33-002.44-089.856$

\section{ХИРУРГИЧЕСКАЯ КОРРЕКЦИЯ КИСЛОТОПРОДУЩИРУЮШЕИ ФУНКЦИИ ЖЕЛУДКА МЕТОДОМ СЕЛЕКТИВНОЙ МУКОЗЭКТОМИИ}

\author{
И. А. Салихов, А. А. Агафонов, Д. И. Гафуров
}

Кафедра хирургических болезней (зав.- проф. И. А. Салихов), кафедра топографической анатомии и оперативной хирургии (зав.- проф. А. А. Агафонов) Казанского ордена Трудового Красного Знамени медицинского института имени С. В. Курашова, городская клиническая

больница № 1 имени проф. А. Г. Терегулова (главвраи - А. А. Абдулхаков) г. Казани

Язввенная болезнь желудка и двенадцатиперстной кишки - одно из наиболее распространенных заболеваний пищеварительного тракта. Безуспешность консервативной терапии вынуждает прибегать к оперативному лечению, направленному на подавление основных факторов агрессии, ведущих к ульцерогенезу,- снижению продукции соляной кислоты, пепсина, устранению моторно-эвакуаторных расстройств.

Одним из методов подавления кислото- и пепсинообразования является резекция желудка. Однако это вмешательство нельзя считать безупречным из-за целого ряда тяжелых осложнений послеоперационного периода, связанных в основном с удалением части органа.

Селективная проксимальная ваготомия - вмешательство органосохраняющего типа. Она получила большое распространение как за рубежом, так и у нас в стране [2-6]. Эта операция позволяет значительно снизить кислотность желудка. Наиболее отчетливо еe достоинство выявляется у больных с дуоденальной локализацией язвы при возможности выполнения всех технических ее элементов (мобилизация большой кривизны, детальная препаровка нервно-сосудистых элементов желудка, сохранение ветвей Летарже). При желудочной язве преимущество ваготомии, по мнению ряда авторов $[1,7]$, проявляется менее отчетливо.

В последние годы появились сообщения о возможности снижения секреции методом иссечения слизистой - непосредственного реализатора желудочного сока $[8,9]$. После этой операции регенерирующая на демукозированной поверхности слизистая не будет в полной мере выполнять свою секреторную и кислотообразующую функции, что явится определяющим моментом в лечении язвенной болезни желудка и двенадцатиперстной кишки и приведет к выздоровлению больного.

С учетом морфологических и функциональных особенностей зоны малой кривизны желудка мы решили оказать прессорное воздействие на агрессивные факторы желудочного сока (соляную кислоту, пепсин) путем удаления слизистой оболочки в области малой кривизны с последующим ушиванием демукозированной 